\title{
Micromechanical tensile test investigation to identify elastic and toughness properties of thin nitride compound layers
}

\author{
P. Arnaud ${ }^{(1)}$, E. Heripre ${ }^{(1)^{*}}$, F. Douit ${ }^{(1)}$, V. Aubin ${ }^{(1)}$, S. Fouvry ${ }^{(2)^{*}}$, R. Guiheux ${ }^{(3)^{\star}}$, V. Branger ${ }^{(4)}$, G. Michel $^{(5)}$ \\ (1) Université Paris-Saclay, CentraleSupélec, CNRS, Laboratoire de Mécanique des Sols, Structures et Matériaux, 91190, Gif- \\ sur-Yvette, France. \\ (2) Ecole Centrale de Lyon, LTDS, Ecully, France \\ (3) SAFRAN Transmission Systems, Colombes, France \\ (4) Naval Group, CESMAN, Bouguenais, France \\ (5) IRT-M2P, METZ, France
}

Corresponding authors: eva.heripre@centralesupelec.fr; siegfried.fouvry@ec-lyon.fr; romain.guiheux@safrangroup.com

\begin{abstract}
The measurement of thin-layer mechanical properties, like compounds generated by thermo-chemical nitriding process, is a key issue to optimize and predict the endurance of surface treatment against contact fatigue and wear. An original FIB micro-tensile test strategy involving plain and micro-notched tensile specimens is proposed. These specimens were FIB machined in a thin $\varepsilon(50 \%)-\mathrm{Y}^{\prime}(50 \%)$ compound layer resulting from a common low pressure gaseous nitriding process (Allnit (C) and tested using a dedicated micro-testing system. Combined with DIC analysis, such microtensile test strategy allows extracting both the elastic modulus and the Poisson's ratio. Additionally, testing micro-notched specimens underlines the necessity to include FE simulations in order to take into account the radius of the micro-notch tip as well as the surface roughness induced by the FIB machining process. The investigation of this $\varepsilon-\gamma^{\prime}$ compound layer suggests a Young's modulus $E=$ $200 \mathrm{GPa}$, a Poisson's ratio $\mathrm{v}=0.31$ and a rather low fracture toughness $\mathrm{KIC}=0.55 \mathrm{MPa} \sqrt{\mathbf{m}}$. This methodology involving FIB machining, DIC analysis, test procedures and FE post processing simulations is fully detailed and the given results are discussed regarding literature.
\end{abstract}

Keywords: SEM-FIB; Micro-machining, in-situ micro-tensile test; FIB micro-notched test; KIC

\section{Introduction}

Nitriding is a widely used thermochemical treatment applied to improve the mechanical properties (e.g. hardness, fatigue and wear resistance) of contact surfaces. It is commonly used in contact shafts in power transmission applications. For low-alloyed ferritic steels, this surface treatment is performed between 480 and $580^{\circ} \mathrm{C}$ where diffusing nitrogen molecules react with the alloying elements of steel 
leading to nitride precipitations. The nitrided surface can be divided into three different domains: a thin top surface compound layer, a diffusion layer and an unaffected core. The top compound layer is usually composed of $\gamma^{\prime}-\mathrm{Fe}_{4} \mathrm{~N}$ phase (containing around $6 \% \mathrm{w} N$ ) and $\varepsilon-\mathrm{Fe}_{2-3} \mathrm{~N}$ phase (containing around $11 \% \mathrm{w} N$ ) [1-2]. Literature and industrial feedback suggest that the $\varepsilon-\gamma^{\prime}$ composition, the hardness porosity, and the thickness of compound layer highly influence the wear resistance of the fatigue properties [3-6]. However, most of these investigations are limited to qualitative comparisons and/or empirical wear modeling due to lack of knowledge regarding the mechanical properties of these very thin (less than $30 \mu \mathrm{m}$ ) $\gamma^{\prime}-\varepsilon$ compound layers. Most of the literature work focuses on the hardness and the Young's modulus analysis using nano-indentation approaches [7-14]. Nano-investigation consists in measuring a "reduced" modulus combining the elastic modulus and the Poisson's ratio such that the intrinsic modulus is deduced assuming a Poisson's ratio equals to 0.3. Moreover, the elastic properties and the hardness are not sufficient to detail the fracture behavior of compound layers. Hence, a better knowledge of the fracture toughness $\left(K_{I C}\right)$ properties appears as a key aspect to predict the brittle and fast degradation of compound layers under starved lubrication conditions. Fracture toughness of such thin surface layers can be estimated by applying micro-pillar splitting method as introduced by Sebastiani et al. in [15] then extended to high temperature conditions by Best et al. in [16]. However, this experimental strategy implies complex compressive stress analysis which makes it difficult to compute intrinsic $K_{I C}$ tensile fracture toughness values. Hence, the purpose of this investigation is to propose an alternative micro-notch tensile test analysis [17] which, combined with DIC measurements, allows the decoupled estimation of the Young's modulus and the Poisson's ratio and more originally the computation of the tensile fracture toughness parameter of thin surface layers. This approach is applied to characterize a mixed $\varepsilon-\gamma^{\prime} 10 \mu$ m-thick compound layer obtained using a low pressure gaseous process applied on a 32CrMoV13 low-alloyed steel.

2. Experimental method

2.1. Material

The studied material consists of 32CrMoV13 low steel alloy commonly applied in power transmission systems (Table 1). This alloys displays an elastic Young's modulus E=210 GPa and a Poisson's ratio $v=0.33$. 
Table 1: Composition of 32CrMoV13 steel alloy.

\begin{tabular}{|c|c|c|c|c|c|c|c|c|c|}
\hline element & $\mathbf{C}$ & $\mathbf{S i}$ & $\mathbf{M n}$ & $\mathbf{P}$ & $\mathbf{S}$ & $\mathbf{C r}$ & $\mathbf{N i}$ & Mo & other \\
\hline weight \% & $0.29 \sim 0.36$ & $0.1 \sim 0.4$ & $0.4 \sim 0.7$ & $<0.025$ & $<0.02$ & $2.8 \sim 3.3$ & $<0.3$ & $0.7 \sim 1.2$ & $0.15 \sim 0.35$ \\
\hline
\end{tabular}

A low pressure gaseous nitriding process $(A l l n i t \circledast)$ is applied to generate nitrogen diffusion leading to formation of a mixed $\varepsilon$-phase $\left(\mathrm{Fe}_{2-3} \mathrm{~N}\right)$ and $\gamma^{\prime}$-phase $\left(\mathrm{Fe}_{4} \mathrm{~N}_{1-x}\right)$ compound layer. Dual beam SEM-FIB analyses of cross sections were performed to better characterize the structural composition of the studied compound layer (Fig. 1). The total thickness of the latter is estimated around $9.5 \mu \mathrm{m}$. EBSD transmission analysis of a thin lamella extracted by FIB suggests a $72 \% \varepsilon$-phase and $28 \% \gamma^{\prime}$-phase composition. The EBSD mapping also indicates that the $\varepsilon$-phase is mainly present in the $4 \mu \mathrm{m}$ upper part of the layer where the highest porosity density is also observed. Below $4 \mu \mathrm{m}$, the porosity density decreases and a mixed $50 \% \varepsilon-\gamma^{\prime}$ structure can be observed. The grain size of $\varepsilon$ and $\gamma^{\prime}$ nitride was shown to range from 0.3 to $0.7 \mu \mathrm{m}$.
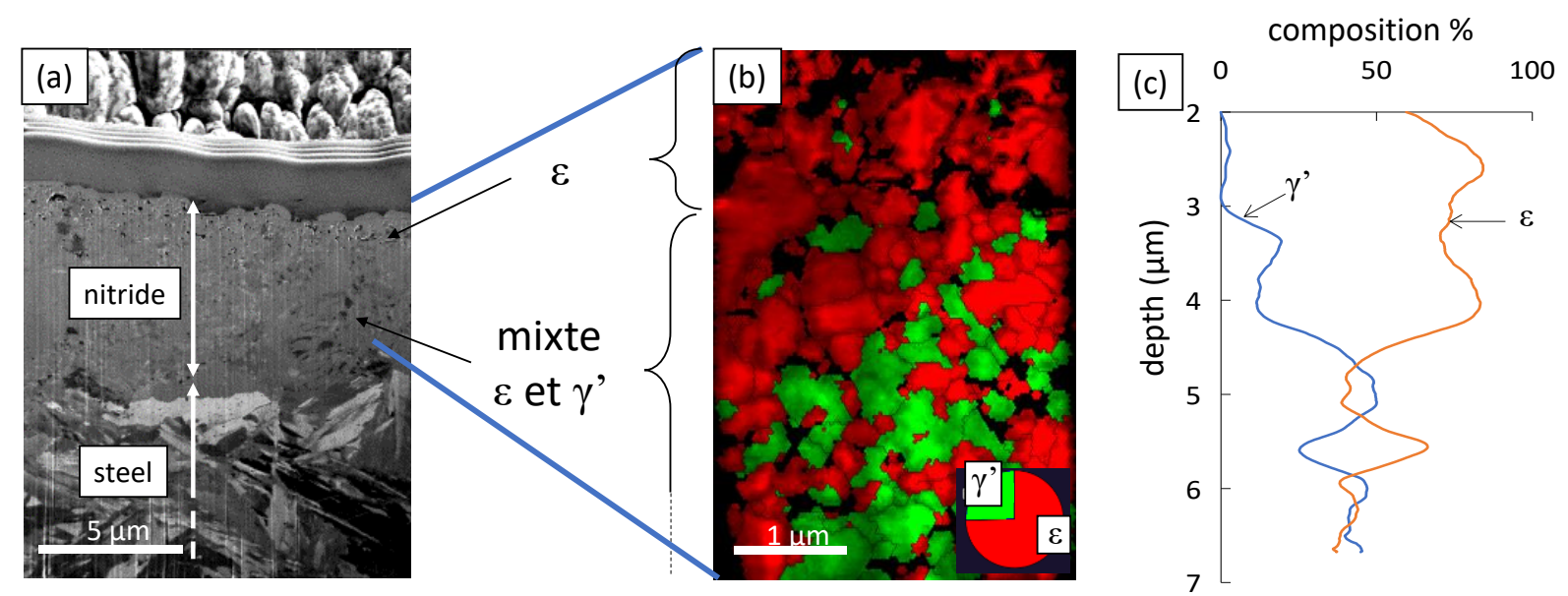

Figure 1: Compound layer of Allnit treatment: (a) SEM observation of a cross-section. First layer is Pt layer added to protect the surface; (b) EBSD analysis; (c) phase concentration as a function of depth.

Larger EBSD analyses including more than 1000 grains were performed suggesting that no preferential direction of the $\varepsilon$-phases and $\gamma$ '-phase can be established; thus, an isotropic behavior of the $\varepsilon-\gamma^{\prime}$ compound layer will be assumed.

Tables 2 and 3 compile the elastic modulus of $\varepsilon$ and $\gamma^{\prime}$ phases obtained from theoretical calculation and nano-indentation respectively. Both simulations and experimental data extracted from the literature propose a $\gamma^{\prime}$ phase elastic modulus $E_{\gamma^{\prime} \text {-phase }} \approx 170 \mathrm{GPa}[7,10,13,14]$. By contrast, 
calculations give an $\varepsilon$-phase elastic modulus around $250 \mathrm{GPa}$ [7-9] which is significantly higher than the experimental values found in the literature ranging between 130 and $200 \mathrm{GPa}$ [11-12]. As illustrated previously, this difference can be explained by the higher porosity usually observed in the $\varepsilon$ phase generated by low pressure gaseous process which tends to decrease and scatter the measured Young's modulus.

Table 2: Theoretical estimations of the elastic modulus and Poisson's ratio of the $\varepsilon$ and $\gamma$ ' iron nitride phases.

\begin{tabular}{|c|c|c|}
\hline Phase & $\begin{array}{c}\text { Elastic modulus } \\
(\mathrm{GPa})\end{array}$ & $\begin{array}{c}\text { Poisson } \\
\text { coefficient }\end{array}$ \\
\hline$\varepsilon[7]$ & 251.4 & 0.28 \\
\hline$\varepsilon[7]$ & 253 & 0.28 \\
\hline$\varepsilon[8]$ & 270 & 0.3 \\
\hline$\varepsilon[9]$ & 249 & 0.32 \\
\hline$Y^{\prime}[7]$ & 178 & 0.34 \\
\hline$Y^{\prime}[10]$ & 168 & $/$ \\
\hline$Y^{\prime}[13]$ & 162 & 0.36 \\
\hline
\end{tabular}

Table 3: Experimental measurements of the elastic modulus of the nitrided steel by nano-indentation.

\begin{tabular}{|c|c|c|}
\hline Phase & Elastic modulus (GPa) & Used Poisson coefficient \\
\hline$\varepsilon[11]$ & 203 & 0.32 \\
\hline$\varepsilon[12]$ & 123 & 0.31 \\
\hline$\varepsilon[12]$ & 165 & 0.31 \\
\hline $\mathrm{Y}^{\prime}[13]$ & 157 & 0.36 \\
\hline $\mathrm{Y}^{\prime}[13]$ & 159 & 0.36 \\
\hline $\mathrm{Y}^{\prime}[14]$ & 172 & No indications \\
\hline
\end{tabular}

To sum up, the extrapolation of the Young's modulus of the studied $\varepsilon-\gamma^{\prime}$ phase from literature data appears quite uncertain. Hence, the first objective of this study is to estimate the Young's modulus from SEM-DIC analysis of the FIB micro-tensile test specimens machined within the given $10 \mu \mathrm{m}$ thick $\varepsilon-\gamma^{\prime}$ compound layer.

\subsection{Experimental procedure}

\subsubsection{In Situ tensile test device}

In situ micro-mechanical experiments were carried out using a test apparatus specially developed at the MSSMAT laboratory [17] (Fig. 2). This micro-test device, involving 3 piezo-electromechanical 
actuators, allows a very accurate positioning while performing tensile as well as bending and compression tests.

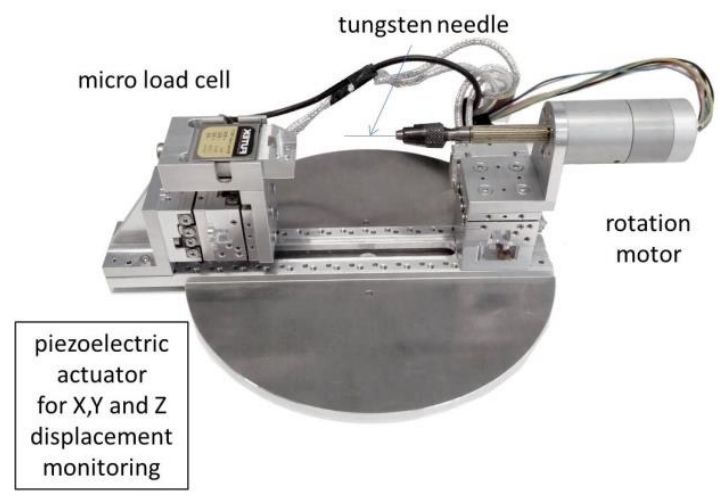

Figure 2: Illustration of the test device developed at the MSSMAT laboratory (Université Paris-Saclay, CentraleSupélec, CNRS) [17].

The loading force can be applied between 5 and $500 \mathrm{mN}$ with a $0.5 \mathrm{mN}$ resolution. However, the measured displacement of the grips stage corresponds to the test compliance accommodation and cannot be considered to estimate the specimen deformation. A DIC in situ analysis is therefore performed to measure the true $\varepsilon$ strain field on the tensile-test specimen.

\subsubsection{SEM imaging}

SEM pictures are acquired with $3 \mathrm{~K} \times 2 \mathrm{~K}$ resolution on 8 bits which provide 256 grey levels. The brightness and contrast were optimized in order to avoid saturation and save information using the entire grey scale. The horizontal field width is $75 \mu \mathrm{m}$ which gives $50 \mu \mathrm{m}$ in the vertical direction. The scan speed is $5 \mu$ s per point, thus the time acquisition is $32.2 \mathrm{~s}$ per picture. A BSE (backscattered electron) detector was used with an incident electron beam of $15 \mathrm{kV}$ acceleration voltage and a $1.6 \mathrm{nA}$ current to have pictures with high contrast [18].

2.2.3. Strain measurement by global digital image correlation

A usual global Digital Image Correlation analysis, extensively developed during the past decades by Hild and co-authors was applied [20, 21]. The problem is decomposed in several degrees of freedom which should be determined by minimizing the global correlation error or the DIC cost function. This error $(\eta)$ is the difference in the observed grey intensity between the reference image $(f)$ and the deformed image $(g)$ corrected by the measured displacement field $(\vec{U})$. 
$\eta=\sqrt{\frac{1}{N_{k}} \sum_{k=1}^{N_{k}}\left(f_{k}-\hat{g}_{k}\right)^{2}}$

Where $N_{k}$ is the number of pixels considered in the region of interest $(\mathrm{ROI})$ and $\hat{g}_{k}$ is the grey level at the location $(k)+\vec{U}_{k}$ in the image $g, \mathrm{k}$ is characterized by a couple $(x, y)$. These approaches are generally coupled with a finite element $(\mathrm{FE})$ model to have a direct access to the deformation and the stress fields of the mechanical problem. In the present investigation, a Fourier's polynomial base is considered to describe the displacement fields. Then, a simple regularization using the LevenbergMarquardt method is applied to accelerate the convergence [22].

\subsubsection{Micro-specimen manufacturing process}

\section{Manufacturing tensile-test specimen}

A FIB excavation manufacturing process was first performed using a $9.3 \mu \mathrm{A}$ current with $30 \mathrm{kV}$ accelerating voltage to extract the draft specimen shape from the $\varepsilon-\gamma^{\prime}$ compound layer. Then, the current was lowered to $0.21 \mathrm{nA}$ for the final surface machining of the micro-tensile test specimens to minimize the ion-induced damage. The principle of the extraction of the tensile-test specimen is illustrated in Fig. 3. A thin $100 \mu \mathrm{m}$ layer including the compound layer but also a part of the steel material is initially extracted from the nitride coupon using a diamond wire cutting (Fig. 3a). Then, from the cross-section side, two lateral top and bottom millings are done to select the compound layer domain where the mechanical properties will be identified (Fig. 3b). The resulting "effective" layer is adjusted to achieve the required specimen thickness. Finally, a FIB contour machining is applied to obtain the final tensile micro-specimen (Fig. 4). The extraction of the micro-tensile test specimens was performed in the middle of the compound layer where nearly an equipartition (i.e. $50 \%$ proportion) of the $\varepsilon$ and $\gamma^{\prime}$ phases is observed. 

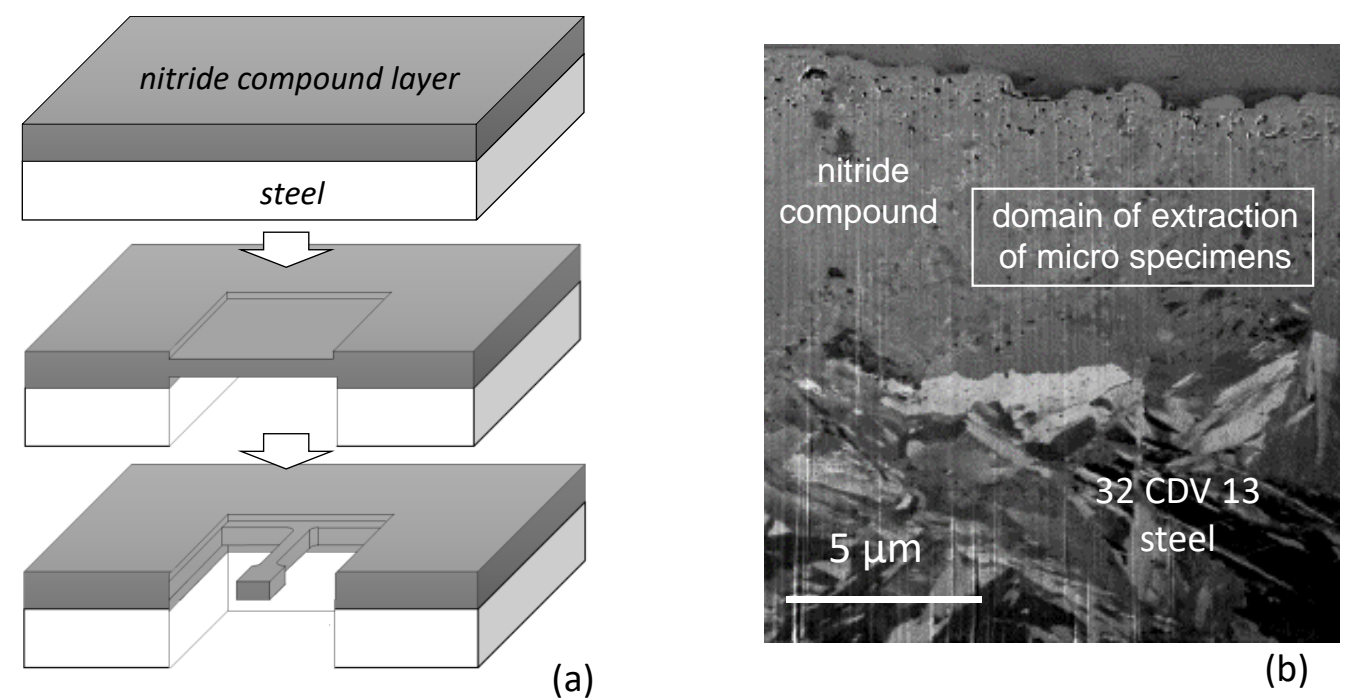

(a)

(b)

Figure 3: (a) Illustration of the different steps related to the manufacturing process of a FIB microtensile test specimen in a compound layer; (b) identification of the domain where the micro-tensile test specimens are extracted.

\section{Specimen Geometry}

Fig. 4 illustrates the tensile specimen shape adopted for the given micro-test analysis. The methodology introduced by [23] will be considered where one side of the specimen remains fixed to the bulk material. Specific micro-specimen grips were previously FIB-machined at the tip of the tungsten needle of the test system (Fig. 2). The thickness of the specimen is between 3 and $6 \mu \mathrm{m}$, whereas the gauge length was fixed at $30 \mu \mathrm{m}$. Table 4 compiles the used dimensions of the studied micro-specimens. The section of the specimens is between 40 and $60 \mu \mathrm{m}^{2}$. The former EBSD investigation suggests a nitride grain size lower than $0.7 \mu \mathrm{m}$, which therefore supports the hypothesis of a representative mechanical behavior. Moreover, the crystallographic texture analyzed by EBSD reflects an isotropic behavior. To reduce the FIB manufacturing cost, the contour machining process is duplicated in order to extract two tensile specimens (T1 \& T2) as illustrated in Fig. 4c. After the low current etching process, a speckle pattern is applied on the top surface of the effective pulling area for the DIC analysis. It consists in applying a pseudo random electronic platinum patch. This latter was performed by e-beam induced deposition (EBID) [21] with a $5 \mathrm{kV}$ acceleration voltage, a $0.8 \mathrm{nA}$ current, and a dwell time of $50 \mu$ s with 736 passes and using a black and white image of a pseudorandom pattern. 


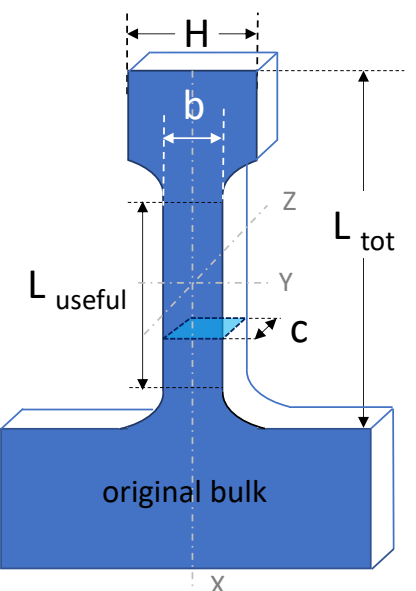

(a)

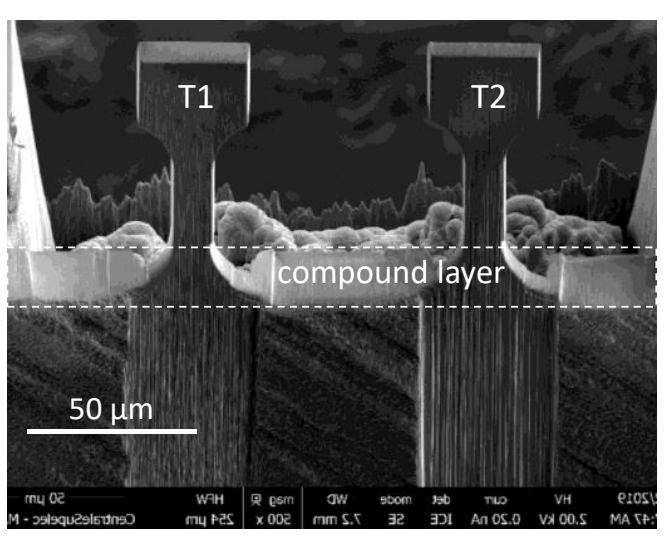

(b)

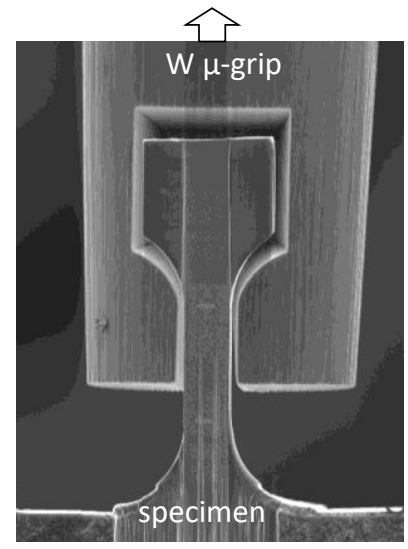

(c)

Figure 4: (a) Geometry of the tensile sample; (b) SEM top view of the micro-tensile test specimens after FIB machining; (c) sample and grips machine before tensile test.

As previously mentioned, the upper $4 \mu \mathrm{m}$ of the layer consists mainly of a porous $\varepsilon$-phase. Hence, the micro-tensile specimens were extracted from the deeper part where a dense mixed $\varepsilon-\gamma^{\prime}$-phase nitride layer can be detected. Two specimens were FIB-machined displaying $3.5 \mu \mathrm{m}$ (T1) and $5.3 \mu \mathrm{m}$ (T2) thicknesses respectively. The global dimensions of T1 and T2 specimens are shown in Table 4.

Table 4: Geometry of the tensile-test specimens extracted within the compound layer (Fig. 4a).

\begin{tabular}{|l|l|l|l|l|l|l|l|}
\hline Sample & $\mathrm{H}(\mu \mathrm{m})$ & $\mathrm{b}(\mu \mathrm{m})$ & $\mathrm{c}(\mu \mathrm{m})$ & $\mathrm{L}_{\text {useful }}(\mu \mathrm{m})$ & $\mathrm{R}(\mu \mathrm{m})$ & $\mathrm{S}\left(\mu \mathrm{m}^{2}\right)$ & $\mathrm{L}_{\text {tot }}(\mu \mathrm{m})$ \\
\hline $\mathrm{T} 1$ & 15 & 11.9 & 3.5 & 30 & 20 & 41.6 & 77 \\
\hline T2 & 15 & 11.3 & 5.3 & 30 & 20 & 59.9 & 77 \\
\hline
\end{tabular}

\section{Results}

\subsection{Identification of the elastic properties}

For each T1 and T2 specimens, tensile tests were performed by increasing incrementally the displacement imposed on the grips. At the end of each increment, the tensile force and the picture of the SEM speckle pattern are recorded. Then, DIC analysis is performed to extract the corresponding strain deformation over the pulling domain in the ROI (Fig. 5). A rather homogeneous strain field is observed with a mean residue around $6 \%$ of the grey scale. This rather high residue may be interpreted by brightness and contrast fluctuations during the test. However, it remains wellsuperimposed with the reference image (Fig. 6b) indicating that a good correlation analysis is performed. 

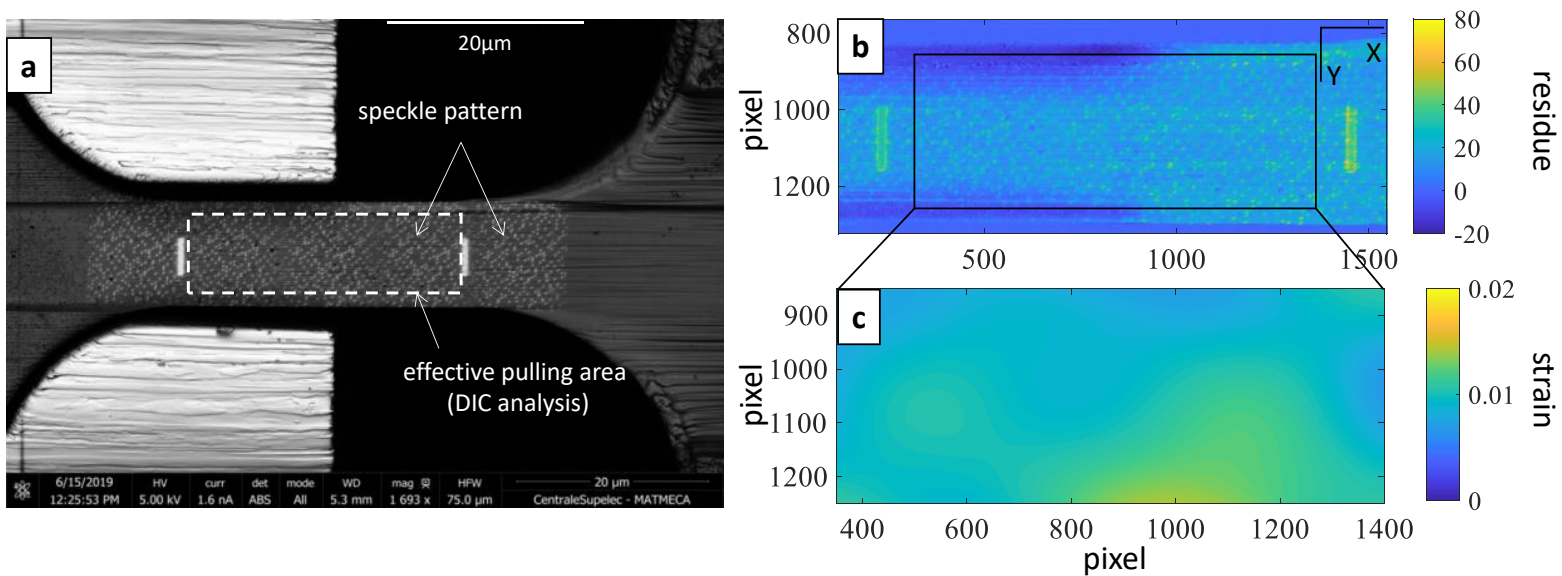

Figure 5: (a) Illustration of the pseudo random platinum patch used for the DIC analysis; (b) the residue of the correlation (in \% of grey level); (c) the obtained local strain in the tensile direction.

Knowing the section area of each specimen (Table 4), the stress-strain $(\sigma-\varepsilon)$ tensile curves can be plotted (Fig. 7). Regarding the strain value, a standard deviation analysis is performed from the strain field measurement over the whole region of interest. The ROI is delimited in a rectangular domain on the $L_{\text {useful }} \times$ b flat surface (Fig. $4 \& 5 a$ ) at least at $1 \mu \mathrm{m}$ from the markers and the specimen edges to avoid any geometrical artefacts potentially induced by the FIB milling process. A non-perfect homogeneous strain distribution is noticed which can be explained by the small misalignment between the sample and the grips and potentially by the inhomogeneous distribution of $\varepsilon-\gamma^{\prime}$ phases previously deduced from the EBSD analysis (Fig. 1). A standard deviation analysis of the stress evolution is also considered taking into account the specimen geometry force resolution scatterings.
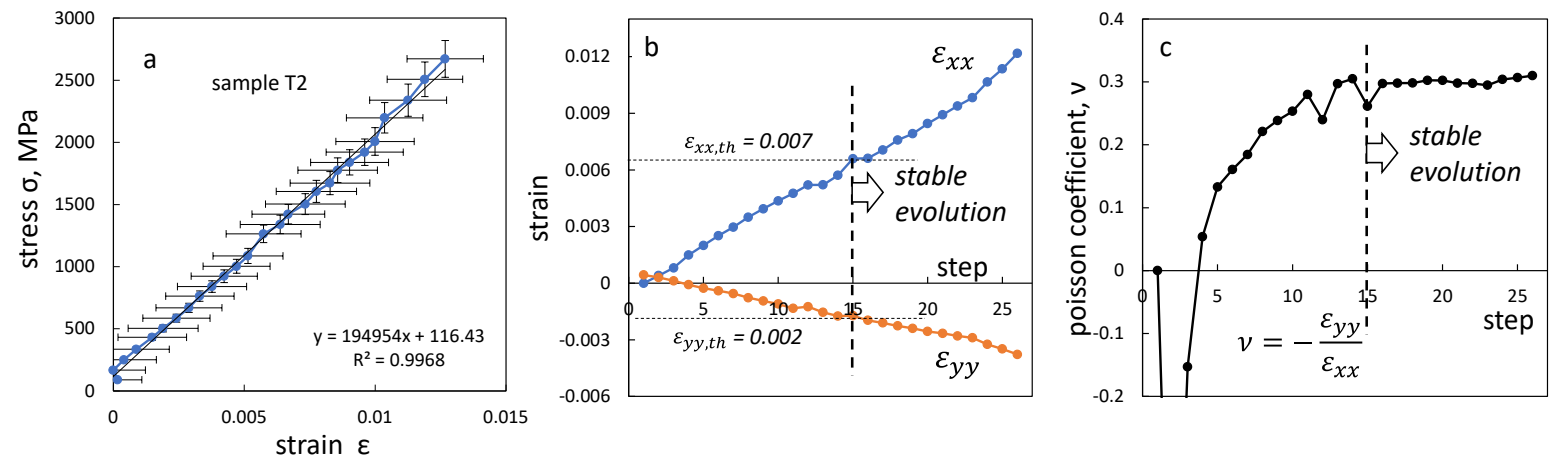

Figure 6: (a) Stress-strain $(\sigma-\varepsilon)$ tensile curves of the specimen T2; (b) strain evolution $\varepsilon_{x x}$ and $\varepsilon_{y y}$ for each step; (c) the calculated Poisson coefficient from the tensile test.

A larger discrepancy is observed at the beginning of the test, below $300 \mathrm{MPa}$, due to the very low stress-strain level. Then, the scattering decreases and stabilizes. Linear evolutions can be 
approximated allowing the extrapolation of $E_{(T 1)}=214 \mathrm{GPa}$ and $E_{(T 2)}=195 \mathrm{GPa}$ elastic modulus (Table 3). It is interesting to note that these values, are comprised between the two theoretical $\varepsilon$ (i.e. $E_{\varepsilon}=250$ $\mathrm{GPa})$ and $\gamma^{\prime}$ (i.e. $E_{\gamma^{\prime}}=170 \mathrm{GPa}$ ) elastic modulus values $[7,10,13]$. In fact, assuming the VRH (VoigtReuss-Hill) [25] and knowing the relative proportion of each phases which, after the given EBSD analysis, is about 50\%, a mixed theoretical $\varepsilon-\gamma^{\prime}$ Young modulus $\mathrm{E}=204 \mathrm{GPa}$ can be estimated. This value is very close to the averaged value deduced from the experiments ( $\approx 204.5 \mathrm{GPa}$ ). Such very nice correlation suggests that the given micro-tensile test combined with DIC analysis appears as an interesting test procedure to characterize the elastic properties of thin layers. Beside, DIC analysis also permits the extraction of both $\varepsilon_{x x}$ and $\varepsilon_{y y}$ strains' evolutions (Fig. 6b) and consequently the estimation of the Poisson's ratio (i.e. $v=-\varepsilon_{y y} / \varepsilon_{x x}$ ). As illustrated in Fig. 6c, after a transient period characterized by a significant scattering induced by the measurement of the very small strain deformations, the Poisson coefficient stabilized around $v=0.32$ which is consistent with theoretical values derived from literature. From this investigation it can be also concluded that reliable estimations of the Poisson's ratio can only be achieved when the $\varepsilon_{y y}$ micro-strain overpasses $2.10^{-3}$ (i.e. the $\varepsilon_{x x}$ micro-strain overpasses $7.10^{-3}$ ).

\subsection{Fracture toughness test}

\subsubsection{Geometry and tests}

Compound layers are known to display very brittle behavior. Hence, knowing the fracture toughness of such nitride structures seems interesting to better formalize the wear performance of nitriding surface treatments. Very few studies have been done to quantify the fracture toughness of the nitride compound layer. For instance, Fu et al. [26] investigated the evolution of the toughness property of steel subjected to different nitriding treatments using a Charpy U-notch methodology. In this analysis, by decoupling the fracture toughness of the steel bulk, the diffusion layer and finally the nitride compound layer, the authors underlined a net decrease of the fracture energy from 32 to $5 \mathrm{~J}$. Postmortem observations of the fractured surfaces showed a quasi-cleavage morphology for the nitrided steel specimens whereas the untreated steel displayed a pure ductile behavior. To determine the intrinsic fracture toughness values of the very thin layers, alternative micromechanical testing procedures are required [27]. Nolan et al. [28], applying the formulation given by Shetty et al. [29], estimated the fracture toughness of the compound layer by measuring the averaged surface crack 
length generated at the corners of macro-Vickers indents (i.e. to $600 \mathrm{~N}$ ). Varying the indentation load, they extrapolated the fracture toughness which had a value around $6 \mathrm{MPa} \sqrt{\mathrm{m}}$. However, this method involves the steel substrate material which is much more ductile than the nitride layer and therefore tends to over-estimate the fracture toughness of the compound layer. One alternative to establish the fracture toughness of thin layers consists of a notched micro-cantilever bending test. By measuring the fracture force and taking into account the geometry of the micro-beam and notch defect, a simple analytical formulation allows the estimation of fracture toughness assuming linear elastic fracture mechanics. Considering this former development, a micro-tensile notched specimen is presently developed to study the fracture toughness behavior of the studied thin nitride compound layers. A second set of the micro-tensile test specimens was machined, equivalent to the former T1 and T2 specimens but including symmetrical notches located at each lateral side of the sample. The FIB milling process was performed with a $30 \mathrm{kV}$ acc. tension and an $80 \mathrm{pA}$ current. Fig. 7 illustrates the geometries of the studied notched tensile test specimens.

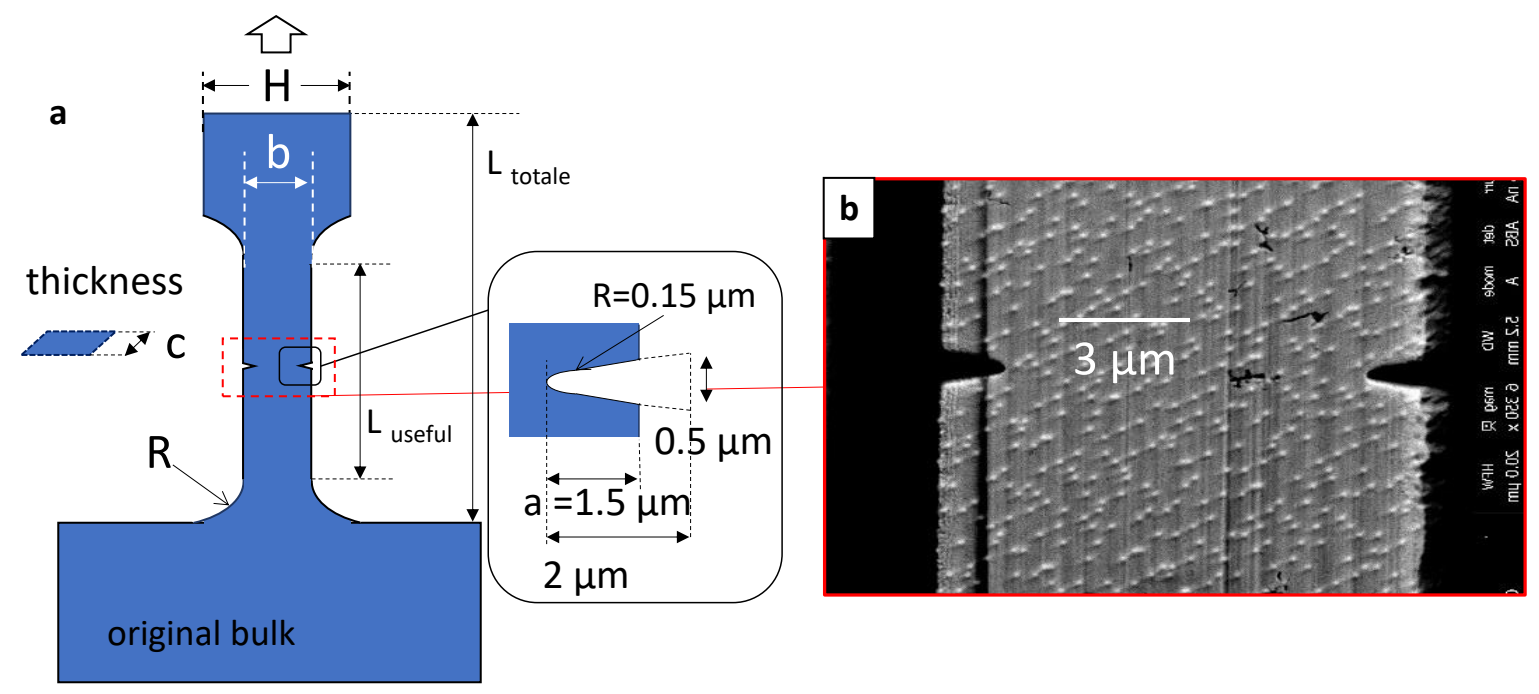

Figure 7: (a) Geometry of the notched micro-tensile test specimen; (b) SEM image of the notched micro-tensile test specimen.

Two notched specimens, N1 and N2, were FIB-machined at $4 \mu \mathrm{m}$ depth below the top surface in the middle part of the compound layer thickness where a similar 50\% distribution of $\varepsilon$ and $\gamma^{\prime}$ phases is identified. The geometrical parameters of these two specimens are compiled in Table 5.

Table 5: Geometrical parameters of the notched tensile test specimens.

\begin{tabular}{|c|c|c|c|c|c|c|c|c|c|c|}
\hline $\begin{array}{c}\text { Notch } \\
\text { sample }\end{array}$ & $\mathrm{H}(\mu \mathrm{m})$ & $\mathrm{b}(\mu \mathrm{m})$ & $\mathrm{c}(\mu \mathrm{m})$ & $\begin{array}{c}\mathrm{a} \\
(\mu \mathrm{m})\end{array}$ & $\begin{array}{c}\mathrm{L}_{\text {useful }} \\
(\mu \mathrm{m})\end{array}$ & $\begin{array}{c}\mathrm{R} \\
(\mu \mathrm{m})\end{array}$ & $\begin{array}{c}\mathrm{L}_{\text {tot }} \\
(\mu \mathrm{m})\end{array}$ & $\begin{array}{c}\mathrm{S} \\
\left(\mu \mathrm{m}^{2}\right)\end{array}$ & $\begin{array}{c}F_{\text {failure }} \\
(\mathrm{mN})\end{array}$ & $\begin{array}{c}\sigma_{\text {failure }} \\
(\mathrm{MPa})\end{array}$ \\
\hline $\mathrm{N} 1$ & 15 & 9.9 & 4.9 & 1.44 & 30 & 20 & 77 & 48 & 31 & 643 \\
\hline $\mathrm{N} 2$ & 15 & 10.4 & 4.8 & 1.65 & 30 & 20 & 77 & 49.7 & 26 & 519 \\
\hline
\end{tabular}


Tensile tests were performed and failures were clearly observed at the notch position (Fig. 8). Brittle fractures without any sign of plasticity have been noticed. The nominal fracture stresses were $\sigma_{\text {failure }}=$ 643 and $519 \mathrm{MPa}$ for the specimens N1 and N2 respectively.
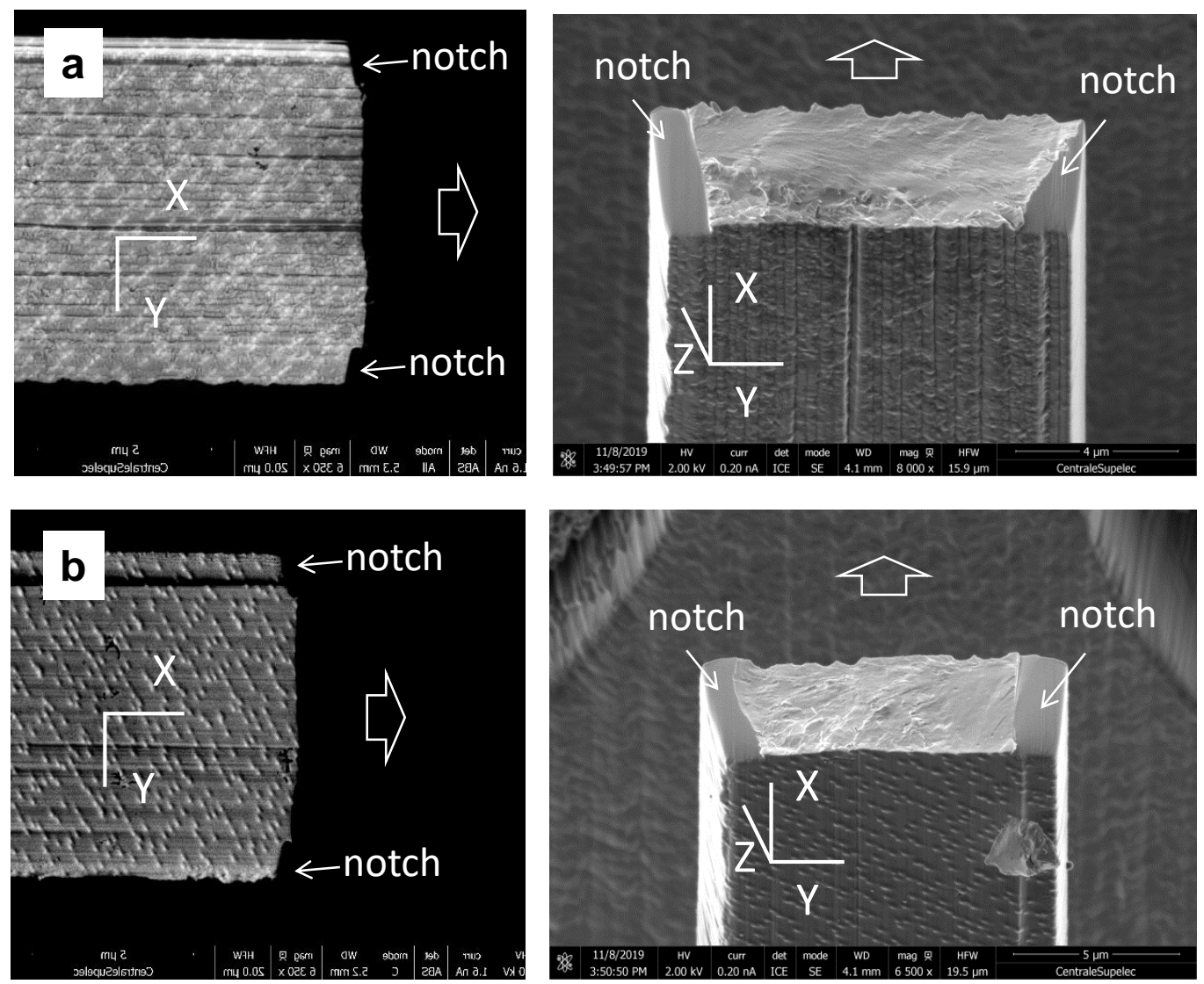

Figure 8: Observation of the fractured notched specimens (N1: $\sigma_{\text {failure }, N 1}=643 \mathrm{MPa}$; N2:

$$
\sigma_{\text {failure, } N 2}=519 \mathrm{MPa} \text { ): (a) specimen N1; (b) specimen N2. }
$$

\subsubsection{Analytical estimation of the fracture toughness (ideal sharp notch hypothesis)}

Assuming theoretical geometries (i.e. notch radius equals to zero), Tada et al. [30] plane strain formulation can be considered to estimate the $K_{I C, A}$ analytical fracture toughness:

$K_{\text {Ic }}=\sigma_{\text {failure }} \sqrt{\pi a} \times F\left(\frac{2 a}{b}\right)$

Where $F$ is the correction function due to the geometry given by Tada [29]:

$F\left(\frac{2 a}{b}\right)=\frac{1.122-0.561\left(\frac{2 a}{b}\right)-0.205\left(\frac{2 a}{b}\right)^{2}+0.471\left(\frac{2 a}{b}\right)^{3}-0.190\left(\frac{2 a}{b}\right)^{4}}{\sqrt{1-\frac{2 a}{b}}}$

"a" and "b" are the crack length (i.e. the notch length) and the sample width respectively. This analysis leads to $K_{I C, A-N 1}=1.52 \mathrm{MPa} \sqrt{\mathrm{m}}(\mathrm{a}=1.44 \mu \mathrm{m})$ and $K_{I C, A-N 2}=1.34 \mathrm{MPa} \sqrt{\mathrm{m}}(\mathrm{a}=1.65 \mu \mathrm{m})$. 


\subsubsection{D FE model with ideal sharp notch hypothesis}

The Tada analytical formulation is convenient and easy to apply. However, it does not fully describe the real geometry obtained using FIB machining. Hence, to better describe the real test conditions, a 3D FE model of the specimens was performed. A first FE simulation was performed assuming, as Tada's analytical formulation, ideal notch geometries with a notch radius equals to zero (FEM-1). Nevertheless, this FE modeling takes into account some geometrical defects of the specimens like the fact that the two symmetrical notches are not perfectly aligned along the median $Y$ lateral axis (i.e. at the middle position of the effective tensile specimen length), and display a small eccentricity offset (e). The model considers also the fact that the sample is not perfectly aligned with the tensile force direction but displays a very small $\alpha$ misalignment angle versus the $\mathrm{XY}$ plane. These two geometrical defects, whose parameters are compiled in the last columns of Table 7, are included in the full 3D mesh as illustrated in Fig. 9.

Table 7: Geometrical defects of the notched tensile test samples.

\begin{tabular}{|c|c|c|c|}
\hline Sample & Notch radii, $r$ (side a and b) $(\mathrm{nm})$ & Misalignment, $\alpha\left(^{\circ}\right)$ & Eccentricity, $e(\mu \mathrm{m})$ \\
\hline N1 & $226-189$ & $0.6^{\circ}$ & 0.9 \\
\hline N2 & $130-163$ & $0.7^{\circ}$ & 3.5 \\
\hline
\end{tabular}

Quadratic hexahedron elements were considered assuming elastic properties deduced from the former investigation. One side of the tensile specimen is embedded and the traction force is applied on the opposite part. In contrast to the Tada's formulation which doesn't require any elastic variable to establish the fracture toughness parameter (Eq. 2 \& 3), both elastic modulus and Poisson's ratio of the compound layer are required for the FE analysis since mode I stress intensity factor (SIF) is established from the integral contours [31]. Applying the Abaqus FE specifications [32], the crack tip zone is meshed as a circular domain of 50,120 and $250 \mathrm{~nm}$ radius with $10 \mathrm{~nm}$ hexahedral elements (Fig. 9). The SIF computation of a mixed mode situation is quite complex. However, for the given almost-pure mode I configuration, contour integral analysis provides stable and reliable values whatever the chosen contour. Including experimental eccentricity $(e)$ and misalignment $(\alpha)$, this FE analysis leads to $K_{I C, F E M 1-N 1}=1.5 \mathrm{MPa} \sqrt{\mathrm{m}}$ and $K_{I C, F E M 1-N 2}=1.3 \mathrm{MPa} \sqrt{\mathrm{m}}$ for $\mathrm{N} 1(\mathrm{a}=1.44 \mu \mathrm{m})$ and $\mathrm{N} 2$ $(\mathrm{a}=1.65 \mu \mathrm{m})$ respectively. The difference with the analytical Tada's prediction is less than $3 \%$. This confirms the stability of the given FE analysis proposing that the eccentricity (e) and the misalignment ( $\alpha$ ) defects play a minor role on the SIF estimation. Note that the given FE model, providing a 3D 
description of the specimen, is probably more representative than the $2 \mathrm{D}$ plane strain hypothesis assumed by the Tada's hypothesis.
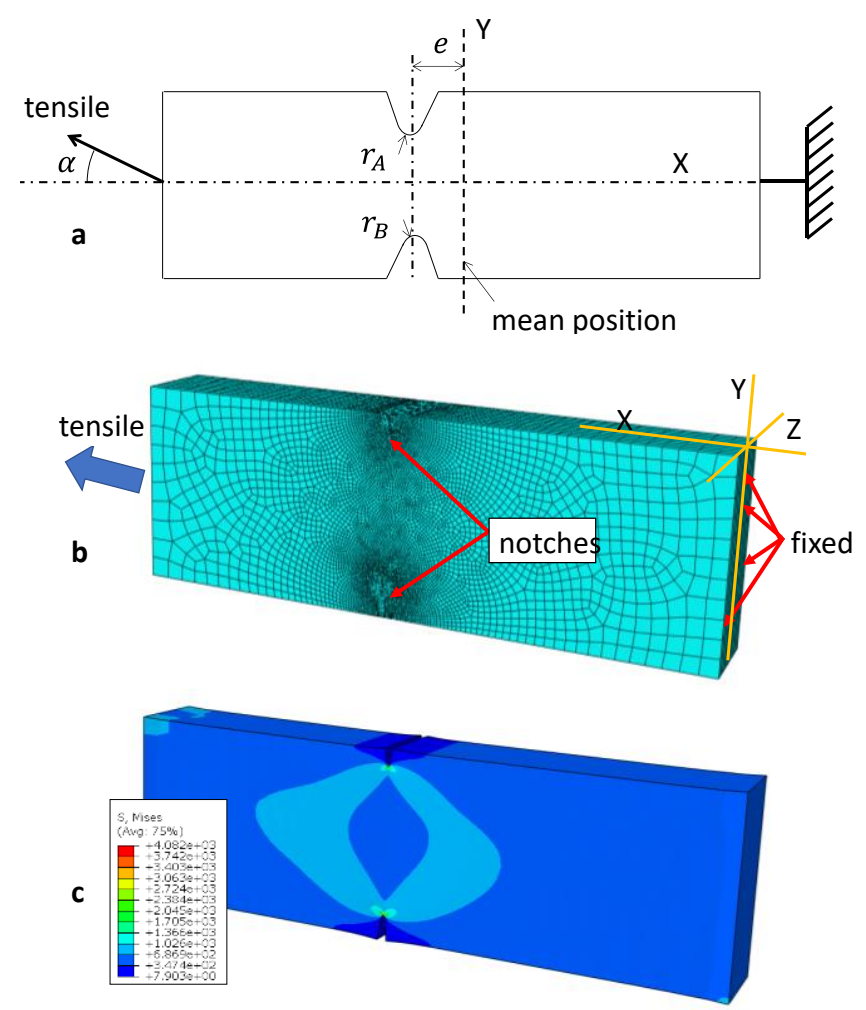

Figure 9: (a) Illustration of the real notched micro-tensile test specimen; (b) FE model of the ideal notched tensile geometry done on the median plane; (c) distribution of the corresponding von Mises stress.

\subsubsection{D FE model with micro-notch radius hypothesis}

As observed in Fig. 7b \&10, the geometry of the notch tip is in fact not so sharp. Indeed, FIB machining process induces notch radii which can be estimated between 100 and $300 \mathrm{~nm}$ (Table 7). These tip radii are very small and could be neglected for conventional macro CT experiments, but for the studied micro-notch experiments they must be considered to estimate reliable fracture toughness values.

FE modeling was then adjusted to include at the tip of each indent the corresponding radius previously estimated from the SEM observation of the specimens before failure. Hence, the FE model was updated to include the inherent experimental defects of the specimens (i.e. $e, \alpha, r_{A}$ and $r_{B}$ ) (Table 7) but still assuming a smooth surface hypothesis. This model, so-called FEM-ES (E: experimental geometry; S: smooth surface) leads to $K_{I C, F E M-E S-N 1}=0.20 \mathrm{MPa} \sqrt{\mathrm{m}}$ and $K_{I C, F E M-E S-N 2}=0.22 \mathrm{MPa} \sqrt{\mathrm{m}}$ fracture toughness estimations for $\mathrm{N} 1(\mathrm{a}=1.44 \mu \mathrm{m})$ and $\mathrm{N} 2(\mathrm{a}=1.65 \mu \mathrm{m})$ specimens respectively. 
A lower dispersion, less than $10 \%$ between $\mathrm{N} 1$ and $\mathrm{N} 2$ estimations is also observed which again confirms the 3D FEM analysis as a pertinent strategy to decrease the scattering of the fracture toughness estimations for the micro-tensile experiments. However, the very small values found, less than 6 times smaller than the former idealized notch radius hypothesis (i.e. $r_{A}=r_{A}=0$ ), suggest that a more precise description of the notch morphologies need be considered to achieve more realistic toughness estimations.
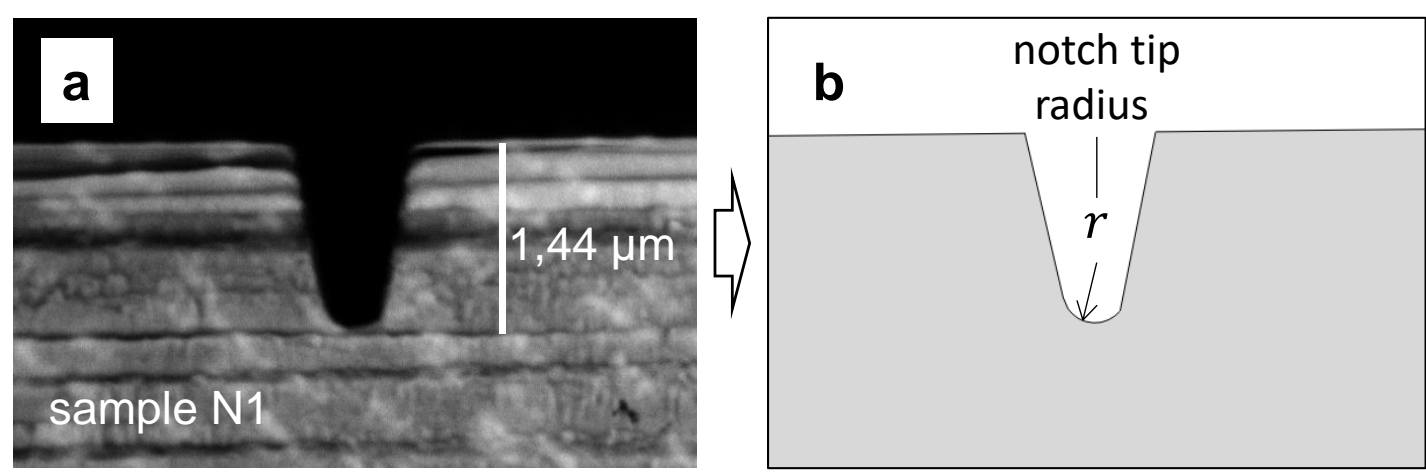

Figure 10: Comparison between experimental and FEM notch shape; (a) secondary electron image of the notch; (b) integration of the micro-notch geometry in the FEM-ES.

\subsubsection{D FEM complete approach (micro-notch radius \& FIB nano-roughness hypothesis)}

The former FEM-ES model better describes the global geometry of the FIB micro-notches but doesn't consider the surface roughness induced by the FIB machining process. Indeed, despite the optimal FIB processing parameters imposed to achieve smooth surfaces, SEM observations reveal a nanosurface roughness which could be approximated assuming a periodic sinusoidal evolution (Fig. 11). Careful observations reveal a period length of about $70 \mathrm{~nm}$ and $90 \mathrm{~nm}$ for the $\mathrm{N} 1$ and $\mathrm{N} 2$ respectively. The wave amplitude $\left(\omega_{\mathrm{a}}\right)$ is more complex to quantify. However, it is possible to approximate the wave amplitude at the crack initiation area (Fig. 11) which was estimated at $\omega_{\mathrm{a}}=60 \mathrm{~nm}$ and $50 \mathrm{~nm}$ for N1 and N2 specimens respectively. Although the surface roughness amplitude is very small, it cannot be neglected when compared to the studied notch geometries. Hence, it must be taken into account to achieve reliable SIF computations. 


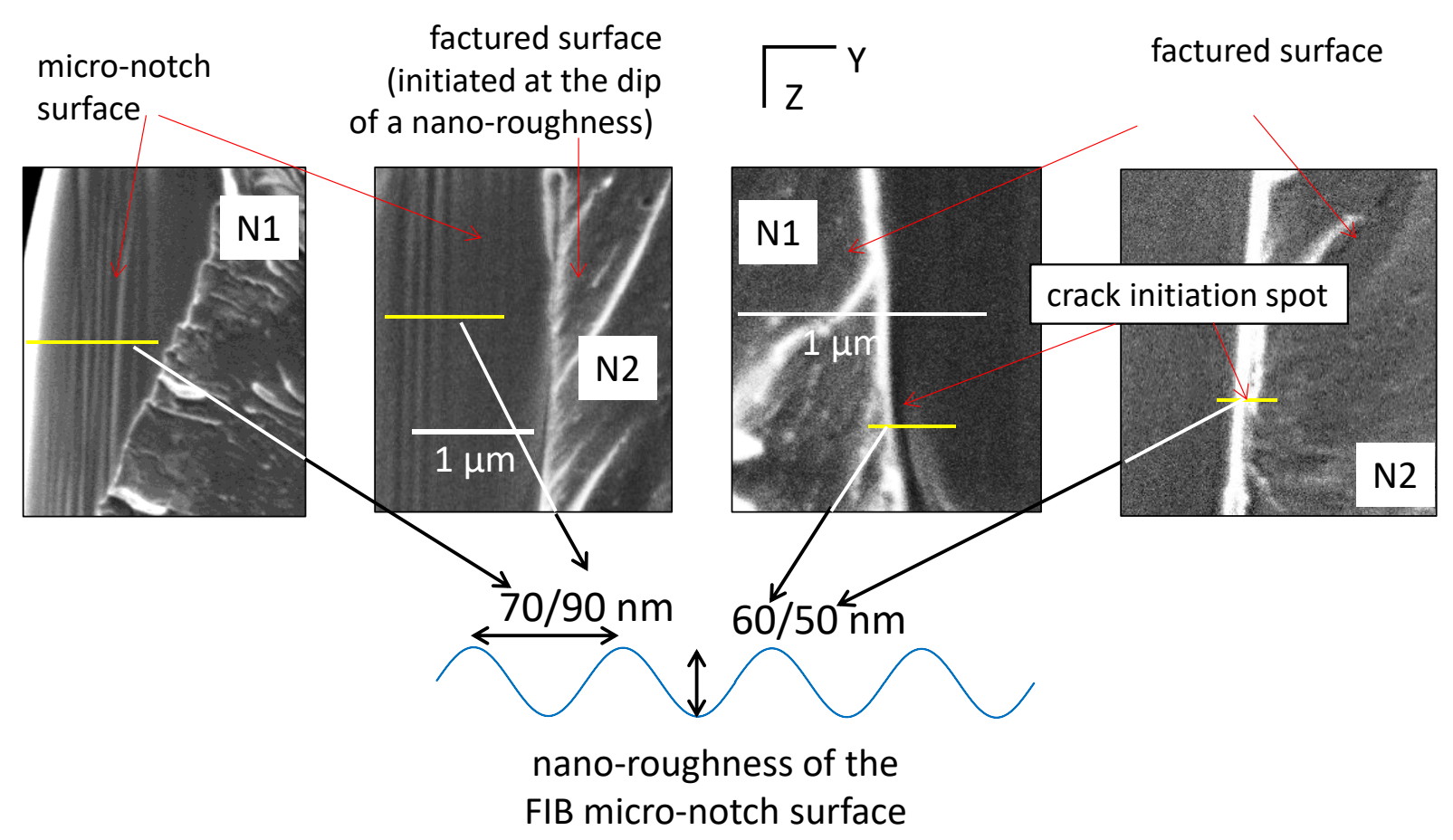

Figure 11: Nano surface roughness of the notch (approximation using a sinusoidal profile).

The strategy to incorporate this nano-roughness effect in the SIF FE analysis is illustrated in Figure 12. It consists of inserting a single nano-notch representative of one period of the nano-sinusoidal surface roughness at the tip of the micro-notch where the maximum stress loading is generated. Note that a similar approach was previously adopted by [33] to predict the effect of the surface roughness regarding fatigue endurance. This proposed nano-notch correction of the micro-notch SIF analysis can be considered as the most conservative approach to estimate the fracture toughness of the studied compound layer.

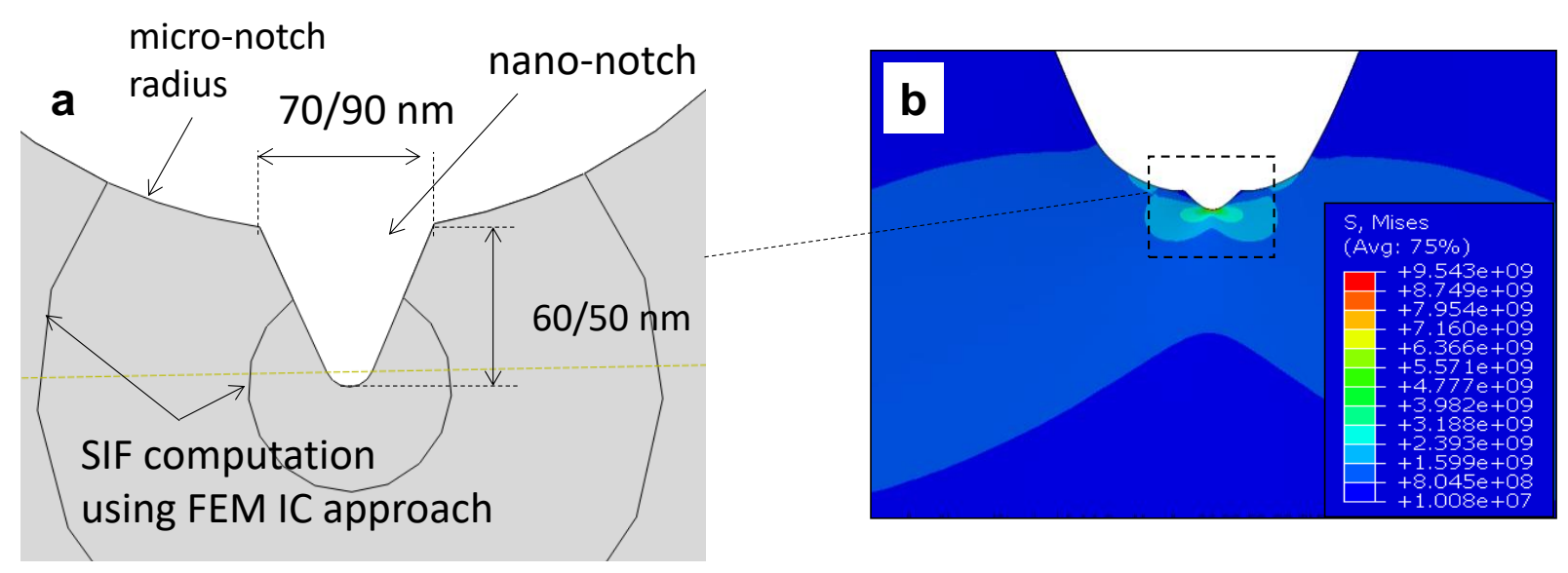

Figure 12: Modeling the effect of FIB nano-roughness by inserting a representative nano-notch at the tip of the micro-notch. 
To achieve this simulation, the mesh size around this nano-notch area was reduced to one nanometer. The other geometrical parameters were kept constant and a similar contour integral method was applied. This extended FEM-ER (E: experimental geometry; R: rough surface) modeling introducing the real micro-notch geometry artifacts but also the FIB surface roughness by including an equivalent nano-notch singularity leads to $K_{I C, F E M-E R-N 1}=0.56 \mathrm{MPa} \sqrt{\mathrm{m}}$ and $K_{I C, F E M-E R-N 2}=0.52 \mathrm{MPa} \sqrt{\mathrm{m}}$ fracture toughness values for N1 and N2 specimens respectively. These values appear more realistic than the former estimations neglecting the FIB surface roughness effect. Besides, these FEM-ER computations reduce the relative dispersion to less than $7 \%$ supporting the stability of the proposal.

\section{Discussion}

This investigation underlines the necessity to combine FEM SIF computations to better interpret FIB micro-notched tensile tests. The four different $K_{I C}$ values extrapolated from the various computation models are compiled in Table 8.

Table 8: Compilation of $K_{I C}$ calculations using different models for both specimens.

\begin{tabular}{|c|c|c|c|c|c|c|}
\hline $\begin{array}{c}\text { Notch } \\
\text { sample }\end{array}$ & $\mathrm{a}(\mu \mathrm{m})$ & $\begin{array}{c}\sigma_{\text {failure }} \\
(\mathrm{MPa})\end{array}$ & $\begin{array}{c}K_{I C-A} \\
(\mathrm{MPa} \sqrt{\mathrm{m}})\end{array}$ & $\begin{array}{c}K_{I C-F E M} \\
(\mathrm{MPa} \sqrt{\mathrm{m}})\end{array}$ & $\begin{array}{c}K_{I C-F E M-E S} \\
(\mathrm{MPa} \sqrt{\mathrm{m}})\end{array}$ & $\begin{array}{c}K_{I C-F E M-E R} \\
(\mathrm{MPa} \sqrt{\mathrm{m}})\end{array}$ \\
\hline $\mathrm{N} 1$ & 1.44 & 643 & 1.52 & 1.5 & 0.20 & 0.56 \\
\hline $\mathrm{N} 2$ & 1.65 & 519 & 1.34 & 1.3 & 0.22 & 0.52 \\
\hline
\end{tabular}

This study reveals that the eccentricity and the misalignment of the specimen play a minor role on $\mathrm{K}_{\mathrm{IC}}$ estimations and can be potentially neglected. However, it demonstrates the necessity to take into account the exact geometry of the micro-notch and more particularly the radius measured at the notch tips before the fracture test. Despite the very careful FIB procedures, these latter are relatively large $(r=0.18 \mu \mathrm{m})$ compared to the total notch length $(\mathrm{a}=1.5 \mu \mathrm{m})$. Hence, the idealized sharp radius hypothesis $(r=0 \mu \mathrm{m})$, commonly applied as in the Tada's formalism for instance, cannot be considered. This explains the huge difference between the theoretical Tada assumption $\left(K_{I C-A}=1.4\right.$ $\mathrm{MPa} \sqrt{\mathrm{m}}$ ) and the FEM simulation taking into account the notch radius but still assuming a smooth surface hypothesis $\left(K_{I C-F E M-E S}=0.2 \mathrm{MPa} \sqrt{\mathrm{m}}\right)$. These two hypotheses must only be considered as the upper and the lower bounds' estimations of the fracture toughness. A better approximation is in fact achieved by applying the complete FEM-ER modeling which takes into account the micro-radius at the notch tip $(r \approx 180 \mu \mathrm{m})$, but also the nano-surface-roughness induced by the FIB machining process by 
superimposing at the notch tip an $\omega_{\mathrm{a}}=60 \mathrm{~nm}$ nano-notch singularity. By considering this more complete description, a more realistic and a less dispersive $K_{I C-F E M-E R}=0.55 \mathrm{MPa} \cdot \sqrt{\mathrm{m}}$ fracture toughness was estimated.

The very large difference with respect to the Nolan et al. [28] results $\left(K_{I C}=6 \mathrm{MPa} \sqrt{\mathrm{m}}\right)$ is not fully understood. One explanation could be the pre-damage induced by the given ion beam machining process of the current small micro-specimens. Note that the thickness of the studied nitride layer was less than $10 \mu \mathrm{m}$, which made it impossible to obtain thicker samples. However, usual TEM investigations suggest that the thickness of metallic materials affected by the ion beam is usually less than $30 \mathrm{~nm}$ which is still very small compared to the section of the current micro-specimens [34]. Moreover, nitride steel is a ceramic material which is in turn less influenced than metals by the ion beam effect. Therefore, the potential pre-damage phenomenon triggered by the ion beam cannot explain the huge difference compared with the Nolan et al. results. A more reliable explanation concerns the volume of the material involved in the $K_{I C}$ estimation. In the current study, only the nitride layer is characterized. By contrast, Nolan et al. [28] analysis, by involving macro-Vickers indents, mobilizes a large quantity of steel from the substrate which can clarify the higher values found. To palliate this effect, the authors decrease the macro-indentation load from $60 \mathrm{~kg}$ to $5 \mathrm{~kg}$. But even at 5 $\mathrm{kg}$ indentation load (i.e. $50 \mathrm{~N}$ ), a plastic deformation is generated in the substrate. Hence, the larger the steel subsurface influence, the higher the estimated value of the fracture toughness of the top nitride layer. Lower indentation loads would be preferred to reduce the relative influence of the steel substrate. However, the indentation method requires a sufficient deformation to activate the crack propagation at the corner edges of the Vickers indents.

Another explanation concerns the effect of the inherent residual stresses generated within the compound layer during the nitriding process. During the FIB preparation of micro-tensile test specimens, most of these compressive residual stresses are released. Hence, it can be assumed that the given $K_{I C-F E M-E R}=0.55 \mathrm{MPa} \cdot \sqrt{\mathrm{m}}$ threshold SIF value estimates well the intrinsic facture toughness of the studied $\varepsilon(50 \%)-\gamma^{\prime}(50 \%)$ nitride compound. On the other hand, the facture toughness values computed using indentation techniques still incorporate the residual stress generated by the nitriding treatment.

A recent study [35] has shown that the compressive residual stresses induced by nitriding treatment in the compound layer can exceed $1000 \mathrm{MPa}$. Hence, to evaluate how the compressive residual stresses 
can influence the estimation of the facture toughness, the same FEM-ER model was applied but including an additional $1000 \mathrm{MPa}$ compressive residual stress state to the material. The threshold SIF value was then established around $1.9 \mathrm{MPa} \sqrt{\mathrm{m}}$ which is closer to the Nolan et al. estimations. From this analysis it can be concluded that a significant part of the difference between the given and the former Nolan et al. estimation of the nitride compound fracture toughness could be related to the presence of residual stresses which still operate during indentation but are nearly fully eliminated using the present micro-tensile notched specimen analysis. Obviously, to clarify this aspect, the most appropriate strategy would consist in analyzing a reference material whose fracture toughness was previously established from macro-standardized tests. Current investigations are undertaken to achieve this objective by investigating amorphous materials to avoid grain size effects between macro and micro test configurations.

In parallel, to palliate the limitations induced by the micro-notch radius and the FIB surface roughness artifact, an equivalent pre-fatigue-cracking strategy as usually applied in macro Compact Tension (CT) experiment, will be examined. This requires a significant amelioration of the actual micro-test machine in order to apply cyclic fatigue stresses. Nonetheless, despite some limitations, the given FIB microtensile test strategy provides many advantages compared to the usual nano-indentation or micro-pillar methods. First, the uniaxial tensile stress state is better controlled and the test is not affected by any compressive hydrostatic stress states as usually observed during indentation tests. Secondly, the micro-tensile test specimens can be extracted at different depths though the layer allowing a local analysis of elastic, plastic and fracture toughness properties as function of the chemical and structural composition through the coating layer. This aspect is very important for heterogeneous surface layers like the studied compound layer but also for most of the layered PVD and CVD surface treatments (i.e. DLC, WC-Co multilayers etc.). Finally, one major advantage of this approach is the possibility to extract micro-tensile test specimens following different directions on the surface plane. Hence, it will permit future investigations of the anisotropic elastic, plastic and facture toughness behaviors of thin coating which are, up to now, not easy to address using indentation methods.

\section{Conclusion}

The estimation of the mechanical properties like elastic and fracture toughness parameters of thin compound layers generated from thermo-chemical nitriding process is a crucial aspect for optimizing and predicting the endurance of such surface treatments against tribological loadings. The 
determination of these mechanical properties is quite complex and implies many assumptions. To palliate such limitations, a micro-tensile test approach is developed involving plain and notched microtensile specimens machined using FIB techniques. This micro-mechanical strategy combining experiments, DIC analysis and FEM computations was applied to characterize the elastic properties and the facture toughness of a thin $\varepsilon-\gamma$ ' compound layer. Such micro-tensile test strategy combined with DIC analysis helps extract the elastic modulus but also the Poisson's ratio of compound layers. The assessment of micro-notched specimens underlines the necessity to combine FE simulations to take into account the radius of the notch tip in addition to the surface roughness which are both induced by the FIB machining process. Following this experimental-FE modeling strategy, fracture toughness properties of the studied $\varepsilon(50 \%)-\gamma^{\prime}(50 \%)$ nitride compound layer can be approximated. The various mechanical properties extracted from this micromechanical analysis are compiled in Table 9.

Table 9: Summary of the mechanical properties of the studied $\varepsilon(50 \%)-\gamma^{\prime}(50 \%)$ nitride compound.

\begin{tabular}{|c|c|c|}
\hline Elastic modulus,E $(\mathrm{GPa})$ & Poisson coefficient, $v$ & Fracture toughness $K_{I C}(\mathrm{MPa} \sqrt{\mathrm{m}})$ \\
\hline 204 & 0.31 & 0.55 \\
\hline
\end{tabular}

Future developments are currently undertaken to apply micro-fatigue loadings in order to quantify the fatigue properties of these thin layers but also to improve the estimation of the fracture toughness value by generating a sharp fatigue crack at the notch tip thus to reproduce as close as possible the stress conditions imposed in classical CT experiments. However, such development is still speculative and could not be elaborated in the framework of this paper. In conclusion, compared with more conventional nano-indentation or micro-pillar compression approaches, the technique proposed in the current paper offers a short-term opportunity to locally study the mechanical properties within a coating layer but also to investigate the anisotropic response of thin surface layers regarding mechanical parameters such as elasticity, plasticity and fracture toughness.

\section{Acknowledgements}

This work was partly financially supported by the IRT-M2P "NITRU" research program. The authors would like to thanks M. J. Neggers from MSSMat for his helpful support regarding residual stress analysis, M. D. Herisson formerly at SAFRAN-STS for his support at the beginning of the project but also all the industrial partners involved in this project, M. O. Skiba from IRT-M2P and, M. C. Dannoux 
from ALD company. This work was carried out within the MATMECA consortium and supported by the ANR under contract number ANR-10-EQPX-37

\section{References}

[1] J. Ratajski, J. Tacikowski, M. A. J. Somers, Development of Compound Layer of Iron(Carbo)Nitrides During Nitriding of Steel, Surface Engineering 19 (2003) 285-292.

[2] E. Menthe, K.-T. Rie, J.W. Schultze, S.Simson, Structure and properties of plasma-nitrided stainless steel, Surface and Coatings Technology 74-75 (1995) 412-416.

[3] S. Karaoğlu, Structural characterization and wear behavior of plasma-nitrided AISI 5140 low-alloy steel, Materials Characterization 49 (2002) 349-357.

[4] K. Marchev, C.V. Cooper, B.C. Giessen, Observation of a compound layer with very low friction coefficient in ion-nitrided martensitic 410 stainless steel, Surf. and Coat. Tech. 99 (1998) 229-233.

[5] C. Binder, T. Bendo, G. Hammes, A.N. Klein, J.D.B. de Mello, Effect of nature of nitride phases on sliding wear of plasma nitrided sintered iron, Wear 332-333 (2015) 995-1005.

[6] J. Baranowska, S.E. Franklin, C.G.N. Pelletier, Tribological behaviour and mechanical properties of low temperature gas nitrided austenitic steel in relation to layer morphology, Wear 259 (2005) 432-438

[7] X. Tan, S. Wang, Y. Chen, Y. Zhou, Z. Li, Design, preparation and characterization of iron nitride magnetic abrasives, Journal of Alloys and Compounds 774 (2019) 443-450.

[8] C.S. Zhang, M.F. Yan, Y. You, H.T. Chen, F.Y. Zhang, B. Bai, L. Chen, Z. Long, R.W. Li, Stability and properties of alloyed $\varepsilon-(\mathrm{Fe} 1-\mathrm{xMx}) 3 \mathrm{~N}$ nitrides $\left(\mathrm{M} 1 \frac{1}{4} \mathrm{Cr}, \mathrm{Ni}, \mathrm{Mo}, \mathrm{V}, \mathrm{Co}, \mathrm{Nb}, \mathrm{Mn}, \mathrm{Ti}\right.$ and $\left.\mathrm{Cu}\right): \mathrm{a}$ first-principles calculations, J. Alloys Compd. 615 (2014) 854-862.

[9] J.S. Chen, C. Yu, H. Lu, Phase stability, magnetism, elastic properties and hardness of binary iron nitrides from first principles, J. Alloys Compd. 625 (2015) 224-230.

[10] Y.Q. Wu, M.F. Yan, Electronic structure and properties of (Fe1-xNix) 4N $(0<x<1.0)$, Physica B 405 (2010) 2700-2705.

[11] R. Niewa, D. Rau, A. Wosylus, K. Meier, M. Hanfland, M. Wessel, R. Dronskowski, D.A. Dzivenko, R. Riedel, U. Schwarz, High pressure-high temperature single crystal growth, ab initio electronic structure calculations and equation of state of $\varepsilon-F e ~ 3 N 1 p x$, Chem. Mater 21 (2009) 392-398.

[12] D. Panfil, M. Kulka, P. Wach, J. Michalski, D. Przestack, Nanomechanical properties of iron nitrides produced on $42 \mathrm{CrMo} 4$ steel by controlled gas nitriding and laser heat treatment, Journal of Alloys and Compounds 706 (2017) 63-75. 
[13] T. Takahashi, J. Burghaus, D. Music, R. Dronskowski, J.M. Schneider, Elastic properties of Y'-Fe $4 \mathrm{~N}$ probed by nanoindentation and ab initio calculation, Acta Mater. 60 (2012) 2054-2060.

[14] A.I. Yurkova, A.V. Byakova, A.V. Belots'ky, Yu. V. Milman, S.N. Dub, Mechanical Behaviour of Nanostructured Iron Fabricated by Severe Plastic Deformation under Diffusion Flow of Nitrogen, Mater Sci Forum (2006) 503-645.

[15] M. Sebastiani, K.E. Johanns, E.G. Herbert, F. Carassiti, G.M. Pharr, A novel pillar indentation splitting test for measuring fracture toughness of thin ceramic coatings, Philos. Mag. 95 (2015) 19281944.

[16] J. P. Best, J. Wehrs, M. Polyakov, M. Morsteinc, J. Michler, High temperature fracture toughness of ceramic coatings evaluated using micro-pillar splitting, Scripta Materialia 162 (2019) 190-194.

[17] G. Ben Salem, E. Heripre, P. Bompard, S. Chapuliot, A. Blouin, C. Jacquemoud, Mechanical behavior characterization of a stainless steel dissimilar metal weld interface : in-situ micro-tensile testing on carburized martensite and austenite, Experimental Mechanics 60 (2020) 1037-1053 (https://doi.org/10.1007/s11340-020-00633-1)

[18] P. Doumalin, Microextensométrie locale par corrélation d'images numériques. Application aux études micromécaniques par microscopie électronique à balayage, $\mathrm{PhD}$ at laboratory LMS, Ecole Polytechnique (2000).

[19] G. Besnard, F. Hild, S. Roux, "Finite-Element" Displacement Fields Analysis from Digital Images: Application to Portevin-Le Châtelier Bands, Experimental Mechanics 46 (6) (2006) 789-803.

[20] J. Réthoré, F. Hild, S. Roux, Shear-band capturing using a multiscale extended digital image correlation technique, Comput. Methods Appl. Mech. Engrg. 196 (2007) 5016-5030.

[21] F. Hild, S. Roux, Comparison of Local and Global Approaches to Digital Image Correlation, Experimental Mechanics 52 (2012) 1503-1519;

[22] Kenneth Levenberg, A Method for the Solution of Certain Non-Linear Problems in Least Squares, Quarterly of Applied Mathematics 2 (1944) 164-168.

[23] D. Kiener, W. Grosinger, G. Dehm, R. Pippan, A further step towards an understanding of sizedependent crystal plasticity: In situ tension experiments of miniaturized single-crystal copper samples, Acta Mater. 56 (2008) 580-592. 
[24] I. Utke, P. Hoffmann, J. Melngailis, Gas-assisted focused electron beam and ion beam processing and fabrication, J. Vac. Sci. Technol., B: Microelectron. Nanometer Struct. Process., Meas., Phenom., 26 (4) (2008) 1197-1276.

[25] R.T. Hill, On discontinuous plastic states, with special reference to localized necking in thin sheets. J. Mech. Phys. Solids 1 (1952) 19-30.

[26] H. Fu, J. Zhang, J. Huang, Y. Lian, C. Zhang, Effect of Temperature on Microstructure, Corrosion Resistance, and Toughness of Salt Bath Nitrided Tool Steel, Journal of Materials Engineering and Performance 25 (2016) 3-8.

[27] J. Ast, M. Ghidelli, K. Durst, M. Göken, M. Sebastiani, A.M. Korsunsky, A review of experimental approaches to fracture toughness evaluation at the micro-scale, Materials \& Design 173 (2019) 1-24.

[28] D. Nolan, V. Leskovsek, M. Jenko, Estimation of fracture toughness of nitride compound layers on tool steelby application of the Vickers indentation method, Surf. \& Coat. Tech. 201 (2006) 182-188.

[29] D.K. Shetty, I.G. Wright, P.N. Mincer, A.H. Clauer, Indentation fracture of WC-Co cermets, J. Mater. Sci. 20 (1985) 1873-1882.

[30] H. Tada, P.C. Paris, G.R. Irwing, The stress analysis of cracks handbook, Del Research Corp., Hellertown, Pa., 1973.

[31] J.R. Rice, A path independent integral and the approximate analysis of strain concentration by notches and cracks. J Appl Mech 35 (1968) 379-386.

[32] Dassault Systems. Abaqus 6.14 online documentation. 2014

[33] B. Vayssette, N. Saintier, C. Bruggera, M. El Maya, E. Pessard, Numerical modeling of surface roughness effect on the fatigue behavior of Ti-6Al-4V obtained by additive manufacturing International Journal of Fatigue 123 (2019) 180-195.

[34] H. Zhu, J. Davis, Z. Li, Crystallographic orientation dependence of radiation damage in Ga-ion irradiated Ni-based alloy processed by a focused ion beam, Nuclear Inst. and Methods in Physics Research B 455 (2019) 83-89.

[35] C. Mansilla, V. Ocelík, J.Th.M. De Hosson, Local residual stress measurements on nitride layers, Materials Science \& Engineering A 636 (2015) 476-483. 